\title{
MANAGEMENT OF CRISES DURING ANESTHESIA AND SURGERY. PART XVII: HYPOTHERMIA AND MALIGNANT HYPERPYREXIA
}

\author{
Salam N Asfar ${ }^{\circledR}$ \& Jasim M Salman ${ }^{\#}$ \\ ${ }^{\circledR} \mathrm{MB}, \mathrm{ChB}$, MSc, Professor of Anesthesiology, College of Medicine, University of Basrah. "MB,ChB, \\ DA, FICMS, Assist. Prof. \& Consultant Anesthesiologist, College of Medicine, University of Basrah, \\ Basrah, IRAQ.
}

\section{Hypothermia}

L ow body temperature can affect the body in many ways such as; $\mathrm{O}_{2}$ dissociation curve shift to the left, acid base balance alteration, cardiovascular system changes, central nervous system will be affected by low cardiac output, metabolism also changed as there will be reduced functions of the liver and kidneys that's why glucose and drugs in minimal doses should be given, electrolyte changes expressed in high serum potassium may affect the cold sensitive heart, as well as there is alters of nondepolarizing agents effect ${ }^{1}$.

Normally, the human body can initiate mechanisms to maintain or generate heat but anesthesia disturbs these homeostatic mechanisms. Along with, exposure to the cold procedural situation and vasodilation induced by general or regional anesthesia contribute to intraoperative hypothermia development ${ }^{2}$.

Causes:

Apart from massive transfusion of cold blood or fluid, the thermoregulatory mechanisms may be impaired during general anesthesia due to vasodilation, radiation \& convection from the skin, and evaporation from the exposed surgical site leading to low body temperature. Elderly patients and long operation cases are more prone, also those who have exposed serous surfaces during surgery such as pleura or bowel ${ }^{3}$.

\section{Signs:}

Low temp, delayed recovery from anesthesia, shivering, dysrhythmias, bradycardia, hypotension and thrombocytopenia ${ }^{4}$.

Monitoring guidelines should be as follows ${ }^{5}$ :

- Body temperature should be observed in the majority of patients undergoing general anesthesia greater than $30 \mathrm{~min}$. in duration.

- Body temperature might preferably be monitored continuously; however, $15 \mathrm{~min}$ periods are most likely enough in nearly all patients.

- Core temperature should be considered throughout spinal or epidural anesthesia in patients whom clinicians believe are probable to become hypothermic.

- Intraoperative core temperatures should typically be maintained $>36^{\circ} \mathrm{C}$ 


\section{Treatment ${ }^{6,7}$ :}

Electric blankets, mattresses or warm-water circulation blankets, forced-air or convective air-warming system, intravenous fluid and blood line warmer, warming of irrigation fluids, heated and humidified breathing circuit, and carbon dioxide warming in laparoscopic surgery. Ensure that operating theatre temperature is 21-24 C, dexamethasone $8 \mathrm{mg}$ IM may be used

\section{Malignant Hyperpyrexia}

An inherited abnormality diagnosed by abnormal levels of creatinine phosphokinase (CPK) in serum, or by muscle biopsy.

Causes $^{8,9}$ :

Triggering agents: mostly suxamethonium, halothane, isoflurane enflurane, sevoflurane desflurane.

Signs $^{10}$ :

High fever, tachycardia, hypercapnea, increased muscle tone specially masseter muscle spasm and rigidity, increased oxygen consumption and cyanosis, and arrhythmias.

Treatment ${ }^{11}$ :

*Lower the body temperature, correct hyperkalemia and acidosis.

*Discontinue anesthesia immediately.

*Hyperventilation with $100 \%$ oxygen.

*Dantrolene sodium $1 \mathrm{mg} / \mathrm{kg}$ IV is the best drug which can be repeated many times over an hour period.

* Glucose 50\% with insulin (100 units per 1 litre) for hyperkalemia.

* Sodium bicarbonate $2-4 \mathrm{mEq} / \mathrm{kg}$ for metabolic acidosis.

*Ice packs, cooling solutions, fan, cold IV and gastric fluid.

* Maintain high urine output by the use of furosemide or mannitol.

*Administer dexamethasone $20 \mathrm{mg}$ or any other steroids.

*Stop the operation if possible, if not, use nitrous oxide in oxygen using a vapour free anesthetic machine with new hoses, opioids, and non-depolarizing muscle relaxants. An alternative is the regional anesthesia using bupivacaine but not lidocaine.

\section{References}

1. Rushman GB, Davies NJH, Cashman JN, Lee's Synopsis of Anaesthesia, Twelfth Edition, ButterworthHeinemann, chapter 2.8, Complications of anaesthesia, P292.

2. Julie R McSwain, Maria Yared, John Wesley Doty, Sylvia H Wilson: Perioperative hypothermia: Causes, consequences and treatment, World J Anesthesiol. Nov 27, 2015; 4(3): 58-65.

3. Daniel I.Sessler; Complications and Treatment of Mild Hypothermia. Anesthesiology 2001;95(2):531-543.

4. Easterbrook PJ, Davis HF. Thrombocytopenia in hypothermia: a common but poorly recognised complication, Br. Med. J. 1985, 291, 23.

5. Checketts MR, Alladi R, Ferguson K, Gemmell L, Handy JM, Klein AA, Love NJ, Misra U, Morris C, Nathanson $\mathrm{MH}$, Rodney GE, Verma R, Pandit JJ; Recommendations for standards of monitoring during anesthesia and recovery Anaesthesia. 2016 Jan;71(1):85-93.

6. Deokkyu Kim; Postoperative Hypothermia, Acute Crit Care. 2019;34(1):79-80.

7. Bräuer A, Quintel M. Forced-air warming: Technology, physical background and practical aspects. Curr Opin Anaesthesiol. 2009;22:769-774.

8.McCarthy EJ. Malignant hyperthermia: pathology, clinical presentation, and treatment. AACN. Clinical issues. 2004;15:232-233.

9. Malignant hyperthermia Association of the united states(MHAUS). MH susceptible patients FAQS.

10. Larach MG, Gronert GA, Allen GC, Brandom BW, Lehman EB; Clinical presentation, treatment, and complications of malignant hyperthermia. Anesth Analg. 2010;110(2):498.

11. Lee C, Durant N, Au E, Katz R; Malignant hyperthermia. Anesthesiology 1981, 54, 61. 